\title{
Examining the Awareness of Turkish Pilgrims on Protection from Respiratory Tract Infections Before the Hajj Visit: A Descriptive Study
}

\author{
(D) Betül Çakmak, (D) Bahar İnkaya \\ Ankara Yıldırım Beyazıt University Faculty of Health Sciences, Department of Nursing, Ankara, Turkey
}

\begin{abstract}
Objective: Hajj is an important form of worship to which a high value is attributed by Muslims. The presence of many pilgrims approximately over the age of 60 together significantly increases the risk of developing respiratory tract infections (RTIs) and viruses [Middle East respiratory syndrome, severe acute respiratory syndrome (SARS), SARS-coronavirus-2]. This study aimed to examine the awareness of Turkish pilgrims on the prevention of infections in the airways before the Hajj visit in 2019.
\end{abstract}

Materials and Methods: A total of 382 Turkish pilgrims traveling to Mecca from Ankara in 2019 constituted the population of the study. The study was conducted in a qualitative and descriptive design. The data were collected through an acquisition information form. The participants were asked to fill out the "Acquisition information form for pilgrim candidates" prepared using a triple scale.

Results: According to the results obtained from the study, 96.9\% of the pilgrim candidates stated that they should wash their hands frequently and $88.7 \%$ of them stated that they use hand sanitizer when they cannot reach any water source. $91.6 \%$ of them indicated that the handkerchiefs they used should be disposable. Over 45\% of the pilgrim candidates stated that they do not know how to use air conditioners and that they do not need to know it. The statistical results showed that there was a significant relationship between the age, gender, chronic disease, educational status of the pilgrims, and their awareness levels on protective factors to prevent RTIs.

Conclusion: Pilgrims are likely to encounter many health problems in the Hajj visits. Therefore, healthcare professionals should be able to determine the accurate care that is needed by pilgrims before and after the hajj. It was determined that pilgrims need training in preventing RTIs.

Keywords: Pilgrims, geriatrics, awareness, respiratory tract infections, nursing

\section{Introduction}

World Health Organization defines a mass gathering as a planned or unplanned event that attracts a large number of people and threatens to exceed the host community's, city's, or county's health planning and response capability (1). These gatherings may be planned or unplanned and recurring or sporadic. The process of Hajj is one of the largest gatherings in the world and every year 2 million pilgrims from more than 180 countries come to Mecca $(2,3)$.

For Muslims, Hajj is an essential act of worship. According to the 2018 official Turkish Hajj report, the overall number of pilgrims heading to Hajj was 77.000 and 52.7 percent of the pilgrims were over 60 years old (4). The collection of large masses poses health hazards due to infectious and non-communicable diseases, as well as environmental factors (e.g. temperature differential, dehydration, hypothermia). Although the Hajj missions last only one week, pilgrims frequently spend the entire month in Saudi Arabia. As a result, pilgrims may face many important health problems during the Hajj season. The most important of these health problems are heat exhaustion, heatstroke, diarrhoeal, skin infections, blood-borne diseases, cardiovascular diseases, trauma risks, and infectious disease risks $(5,6)$. The presence of many pilgrims over the age of 60 together, especially during

Address for Correspondence: Betül Çakmak, Ankara Yıldırım Beyazıt University Faculty of Health Sciences, Department of Nursing, Ankara, Turkey E-mail: betulglchms@gmail.com ORCID: orcid.org/0000-0002-8122-2101

Received: 27.05.2021 Accepted: 20.01.2022

Cite this article as: Çakmak B, Inkaya B. Examining the Awareness of Turkish Pilgrims on Protection from Respiratory Tract Infections Before the Hajj Visit: A Descriptive Study. Eur J Geriatr Gerontol 2022;4(2):85-90

${ }^{\circ}$ Copyright 2022 by the Academic Geriatrics Society / European Journal of Geriatrics and Gerontology published by Galenos Publishing House. 
the Hajj, raises the risk of respiratory tract illnesses (RTIs) (7). Furthermore, due to physical exhaustion, sleep issues, and temperature variances encountered during this journey, each pilgrim's risk of contracting a respiratory system infection rises $(3,8)$.

Infections of the respiratory tract are linked to a variety of acute syndromes and infectious disease processes all over the world. Many viruses are related to these infections, and they generally spread between humans through the respiratory system. As the name suggests, most acute upper respiratory tract infections affect areas of the upper respiratory tract, including the "cold", acute sinusitis, acute laryngitis, conjunctivitis, and otitis media. Viruses in lower respiratory tract infections affect deeper structures below the larynx, including the trachea, bronchi, and bronchoalveolar region, and manifest as bronchiolitis, bronchitis, and acute pneumonia (9). Respiratory diseases are significant public health issues $(10,11)$. According to the literature, the prevalence of respiratory tract infections or symptoms in pilgrims returning from the a pilgrimage ranges from $8 \%$ to $90 \%$ (12-14). According to data reviewed from multiple studies, at least one symptom of respiratory diseases such as cough, expectoration, and dry cough, was reported by pilgrims during the Hajj $(15,16)$. The most common reason for pilgrims to apply to hospitals is respiratory problems. The necessity of RTI prevention strategies has increased as a result of this predicament (17). The causes of symptoms are unknown exactly, but RTI symptoms are caused by a variety of variables that are known by health professionals. Pre-Hajj immunization, masks, disposable handkerchiefs, hand washing, hand hygiene, cough etiquette, social distancing, hand disinfectant, good diet, and proper air conditioning are all recommended by healthcare professionals (18-20). Informing pilgrims via pre-Hajj health workers is one of the methods that are effective in minimizing respiratory infection symptoms, however the literature in Turkey lacks the studies conducted in this field by nurses. This study aims to identify and demonstrate to what extent Turkish pilgrims are knowledgeable about preventing respiratory infections when they are using airways to the Hajj in 2019.

\section{Materials and Methods}

\section{Study population}

The population of the study consisted of 382 Turkish pilgrims traveling from Ankara to Mecca between April 18, 2019 and May 30,2019 , who were interviewed in collaboration with the Turkey Presidency of Religious Affairs. Pilgrims who were older than 18 years old were voluntarily included and all the participants were informed of the necessary explanations before they were provided with the consent form which was obtained from those who agreed to participate in the study.

\section{Sample collection tools}

The participants were requested to complete an "Acquisition information form for pilgrim applicants" which was produced by the researchers using a triple scale in line with the necessary literature (18-20). The questionnaire includes demographic questions with the aim of measuring pilgrims' level of awareness about RTIs before their Hajj visits (e.g. preventive vaccination, using masking, use of disposable handkerchiefs, hand washing, hand hygiene). The data of the study were collected in faceto-face interviews with the pilgrim applicants who visited government facilities for training. The forms of the participants who are illiterate and willing to participate in the study were filled in with the help of the researchers. Filling the form took approximately 5 minutes for each pilgrim.

\section{Research ethics committee permission}

Before the study was conducted, the official permission from the Republic of Turkey Presidency of Religious Affairs was provided to conduct the research, and Ethics committee approval was obtained from Ankara Yıldırım Beyazıt University Clinical Research Ethical Board (2019-no: 16).

\section{Statistics}

SPSS was used to perform the statistical analysis of the data (IBM SPSS Statistics 24). The findings were interpreted using frequency tables and descriptive statistics. The Pearson's chisquare test and Fisher's Exact test were applied to the data in the analysis of the categorical variables. $\mathrm{P}<0.05$ was considered significant.

\section{Results}

\section{Socio-demographic characteristics of the pilgrim candidates and their answers to the questions about protective factors for preventing RTIs}

The mean age of the total 382 pilgrim candidates who participated in the questionnaires was $60 \pm 8.83$. Pilgrim candidates who had only primary school degrees constituted $45.8 \%$ (175 people) of the sample. It was also determined that 89.8\% (343 people) of pilgrim candidates did not smoke and had at least one chronic disease 55.5\% (212 people). Table 1 illustrates the data results of the questionnaire.

What stands out in Table 2 is that most of the pilgrim candidates (96.9\%) stated that they should wash their hands frequently and $88.7 \%$ of them used hand sanitizer when they could not reach any water source. $91.6 \%$ of those who were interviewed indicated that the handkerchiefs they used should be disposable.

According to the findings of the study, $74.9 \%$ of the participants stated that they needed influenza vaccination before going Hajj visit. Another outstanding finding of the study revealed the fact that the participants did not know how to use air conditioners 
and that they did not need to know how to use them, which constitutes $45 \%$ of the sample (Table 2).

\section{The relationship between the demographic characteristics of the pilgrim candidates and the protective factors}

The data analysis revealed that there were statistically significant connections between the age, gender, presence of the chronic condition, educational status of the pilgrim candidates, and

\begin{tabular}{|c|c|}
\hline \multicolumn{2}{|c|}{$\begin{array}{l}\text { Table 1. Socio-demographic characteristics of pilgrim } \\
\text { candidates }\end{array}$} \\
\hline Socio-demographic characteristics $(n=382)$ & n $(\%)$ \\
\hline \multicolumn{2}{|l|}{ Gender } \\
\hline Male & $129(33.8 \%)$ \\
\hline Female & $253(66.2 \%)$ \\
\hline \multicolumn{2}{|l|}{ Age status } \\
\hline $\begin{array}{l}65 \text { years old and under } \\
\text { Over } 65 \text { years old }\end{array}$ & $\begin{array}{l}261(68.3 \%) \\
121(31.7 \%)\end{array}$ \\
\hline \multicolumn{2}{|l|}{ Education status } \\
\hline Illiterate & $23(6.0 \%)$ \\
\hline Primary school & $175(45.8 \%)$ \\
\hline Intermediate school & $58(15.2 \%)$ \\
\hline High school & $90(23.6 \%)$ \\
\hline Bachelor & $35(9.2 \%)$ \\
\hline Master's/doctorate degree & $1(0.3 \%)$ \\
\hline \multicolumn{2}{|l|}{ Smoking status } \\
\hline Smoking & $39(10.2 \%)$ \\
\hline No smoking & $343(89.2 \%)$ \\
\hline \multicolumn{2}{|l|}{ Presence of chronic disease } \\
\hline No chronic disease & $170(44.5 \%)$ \\
\hline 1 chronic disease & $168(44.0 \%)$ \\
\hline 2 chronic diseases & $29(7.6 \%)$ \\
\hline 3 chronic diseases & $12(3.1 \%)$ \\
\hline 4 and above chronic diseases & $3(0.8 \%)$ \\
\hline
\end{tabular}

protective variables to prevent RTIs, according to the answers collected from the 382 Turkish pilgrims (100\%) before traveling to Saudi Arabia.

Our results demonstrated that as the age of the pilgrim candidates decreased, both the status of knowing how to use the air conditioner and the awareness to use the hand sanitizer increased $\left(\chi^{2}=8.990 ; p=0.011, \chi^{2}=7.019 ; p=0.030\right)$.

The other important finding of the study revealed that there was a significant difference between gender and having enough information about protection from RTls. This fact is explained based on the gender of the pilgrim candidates who knew how to use the air conditioner in Hajj $\left(\chi^{2}=13.912, p=0.001\right)$ and who thought that they had enough information about protection from RTI $\left(\chi^{2}=9.342, p=0.009\right)$. One hundred-thirty two $(52.2 \%)$ of the pilgrim candidates who were female stated that they did not know how to use air conditioners or did not need to know while 87 (67.4\%) of them who were male stated that they knew how to use air conditioners. In parallel with this result, it was determined that more than half of the female pilgrim candidates (53.0\%) thought that they had enough information on protection from RTIs, while male pilgrim candidates (67.4\%) had a higher level of knowledge on this subject.

The data analysis also revealed that there were significant connections between the age, gender, chronic disease condition, educational status of the pilgrim candidates, and protective variables to prevent RTIs, according to the answers collected from the 382 Turkish pilgrims (100\%) before traveling to Saudi Arabia $\left(\chi^{2}=9.613, p=0.008\right)$. One-hundred seventy $(80.2 \%)$ of the pilgrim candidates who had at least one chronic disease stated that they knew that they should be an influenza vaccine before the Hajj. The other outstanding and meaningful finding of the study was related to the educational status of pilgrim candidates and their responses to preventive measures. It was determined that with the increase in educational status, the knowledge level

Table 2. Pilgrim candidatesW answers to the questions about protective factors for preventing RTIs

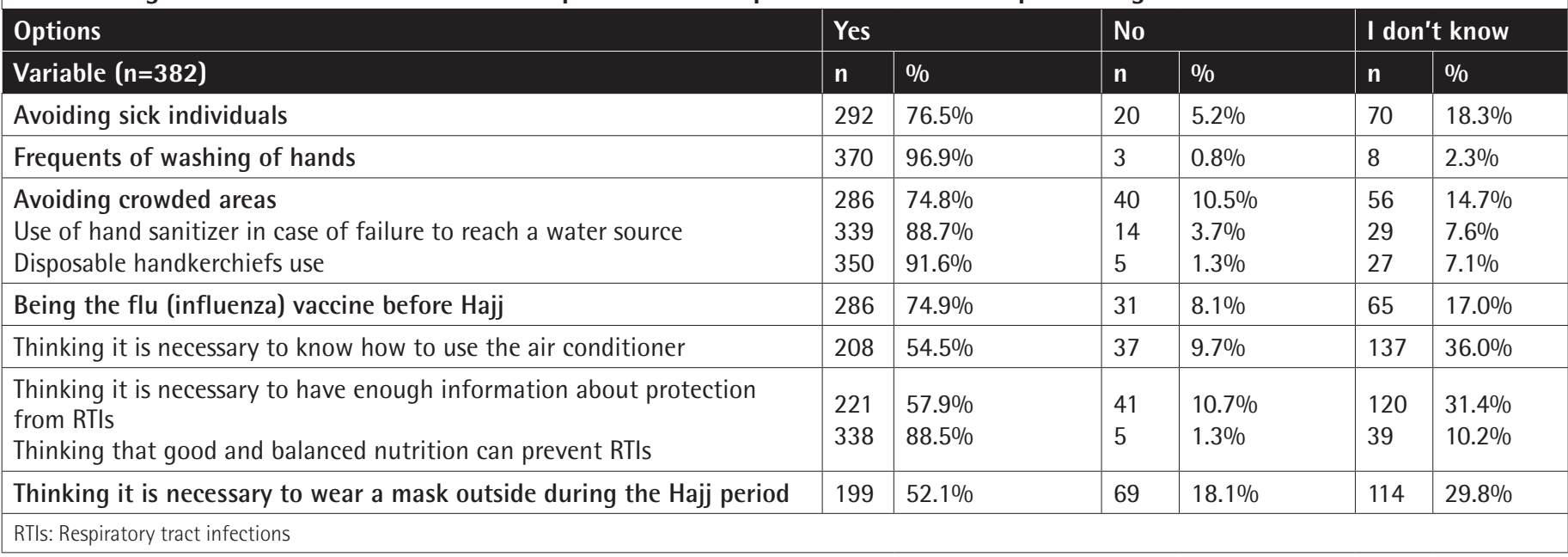


of pilgrim candidates about protective factors had increased. There was a significant relationship between education status and getting the influenza vaccine, and between knowing how to use air conditioners and having enough information about protection from RTls ( $p=0.008, p=0.007, p=0.021$ ) (Table 3 ).

\section{Discussion}

RTI is one of the most important health problems that threaten almost all pilgrim candidates during the Hajj. According to many research results, respiratory tract infection symptoms are the leading causes of hospital admission during and after the Hajj $(15,21,22)$. Therefore, pilgrim candidates must have accurate and enough information about protective measures. Considering the answers given by Turkish pilgrim candidates to the form, they are thought to be very careful about personal issues (hand and face hygiene, disposable handkerchiefs use, etc.). These results are compatible with the literature $(18,20,23)$. However, it was thought that they did not have enough information about influenza vaccination, the use of air conditioning, wearing a mask, avoiding sick individuals, and crowded areas. Whereas, the importance and necessity of mask using, and avoiding sick individuals and crowded areas have been shown in a lot of studies (18).

One of the most important issues in protecting RTI is vaccination. Although it is not a requirement, both the $C D C$ and The Ministry of Health of Saudi Arabia strongly recommend that the pilgrims receive a seasonal influenza vaccine before Hajj $(24,25)$. Unfortunately, the rate of thinking about getting the influenza vaccine before Hajj was found to be $74.9 \%$ in our study. When the result of this analysis is compared with the other researches, it has been seen that the rate is quite inadequate $(23,26)$. In addition, it was determined that having a chronic disease and having a high educational status had a positive effect on pilgrims' vaccination status. Considering that having a chronic illness and a high educational level increase individual awareness and knowledge, we thought that it is important to inform all pilgrims about the importance of vaccination by healthcare professionals (nurses, doctors) before the Hajj. According to these useful findings, it is thought that gender has no impact on knowledge, awareness, and behavior against protection from RTI.

In our study, it was determined that men have more knowledge and awareness about protection from respiratory infections. Although studies on the subject are limited, in a study evaluating pilgrims' vaccination status, men were reported to have more influenza vaccines than women (27). In a meta-analysis in which the effect of gender on behavior to prevent respiratory diseases is evaluated, it has been reported that women are approximately $50 \%$ more likely to apply protective behaviors regarding RTI than men (28). These useful investigations showed that gender does not affect the awareness of respiratory tract infections.

Before long-term visits are planned to any country, it is necessary to obtain information about the factors that may affect our health in the country to be visited. The Hajj is one of

Table 3. Distribution of data on the answers given by pilgrim candidates to questions about protective factors to prevent RTIs

\begin{tabular}{|c|c|c|c|c|c|}
\hline Socio-demographic characteristics & Age & Gender & $\begin{array}{l}\text { Smoking } \\
\text { status }\end{array}$ & $\begin{array}{l}\text { Presence of } \\
\text { chronic disease }\end{array}$ & $\begin{array}{l}\text { Education } \\
\text { status }\end{array}$ \\
\hline Avoiding sick individuals & $\begin{array}{l}x^{2}=5.057 \\
p=0.080\end{array}$ & $\begin{array}{l}x^{2}=1.809 \\
p=0.405\end{array}$ & $\begin{array}{l}x^{2}=0.139 \\
p=0.933\end{array}$ & $x^{2}=0.788 p=0.674$ & $\begin{array}{l}x^{2}=1.858 \\
p=0.762\end{array}$ \\
\hline Frequents washing of hands & $\begin{array}{l}x^{2}=1.878 \\
p=0.391\end{array}$ & $\begin{array}{l}x^{2}=2.117 \\
p=0.347\end{array}$ & $\begin{array}{l}x^{2}=0.351 \\
p=0.839\end{array}$ & $x^{2}=0.626 p=0.731$ & $\begin{array}{l}x^{2}=5.127 \\
p=0.275\end{array}$ \\
\hline Avoiding crowded areas & $\begin{array}{l}x^{2}=2.459 \\
p=0.292\end{array}$ & $\begin{array}{l}x^{2}=2.126 \\
p=0.345\end{array}$ & $\begin{array}{l}x^{2}=3.817 \\
p=0.148\end{array}$ & $x^{2}=4.522 p=0.104$ & $\begin{array}{l}x^{2}=2.121 \\
p=0.714\end{array}$ \\
\hline Disposable handkerchiefs use & $\begin{array}{l}x^{2}=0.637 \\
p=0.727\end{array}$ & $\begin{array}{l}x^{2}=0.735 \\
p=0.692\end{array}$ & $\begin{array}{l}x^{2}=0.039 \\
p=0.980\end{array}$ & $x^{2}=0.646 p=0.724$ & $\begin{array}{l}x^{2}=1.599 \\
p=0.809\end{array}$ \\
\hline To be the flu (influenza) vaccine before Hajj & $\begin{array}{l}x^{2}=1.450 \\
p=0.484\end{array}$ & $\begin{array}{l}x^{2}=0.046 \\
p=0.977\end{array}$ & $\begin{array}{l}x^{2}=0.377 \\
p=0.828\end{array}$ & $x^{2}=9.613 p=0.008^{*}$ & $\begin{array}{l}x^{2}=13.916 \\
p=0.008^{*}\end{array}$ \\
\hline $\begin{array}{l}\text { Thinking that good and balanced nutrition can be } \\
\text { prevented from RTI }\end{array}$ & $\begin{array}{l}x^{2}=0.637 \\
p=0.727\end{array}$ & $\begin{array}{l}x^{2}=0.437 \\
p=0.804\end{array}$ & $\begin{array}{l}x^{2}=0.800 \\
p=0.670\end{array}$ & $x^{2}=1.263 p=0.532$ & $\begin{array}{l}x^{2}=5.815 \\
p=0.214\end{array}$ \\
\hline $\begin{array}{l}\text { Thinking it is necessary to wear a mask outside during the } \\
\text { Hajj period }\end{array}$ & $\begin{array}{l}x^{2}=0.328 \\
p=0.849\end{array}$ & $\begin{array}{l}x^{2}=1.726 \\
p=0.422\end{array}$ & $\begin{array}{l}x^{2}=0.065 \\
p=0.968\end{array}$ & $x^{2}=0.124 p=0.940$ & $\begin{array}{l}x^{2}=8.510 \\
p=0.075\end{array}$ \\
\hline
\end{tabular}


the longest international visits in the world. During the Hajj, in the summer months, daytime temperatures can reach $122^{\circ} \mathrm{F}(50$ ${ }^{\circ} \mathrm{C}$ ), thus climate conditions are also one of the most important topics about which enough information should be collected before traveling. Particularly, the high air temperature poses serious health threats for pilgrims who come from different countries $(24,29)$. There are substantial differences between Turkey and Saudi Arabia on climate conditions. This situation causes more potential health threats for Turkish pilgrims. In Saudi Arabia, there are many air conditioners around the Kaaba in hotel rooms and tunnels to reduce the negative effects of air temperature (24). Despite the poor knowledge, we can say that pilgrims who are traveling from Turkey have high average age, and the education level is generally low. It is thought that these factors increase the risk of Turkish pilgrims becoming ill in Hajj more. By the Directorate of Religious Affairs of Turkey, it is distributed a handbook to all pilgrims before every Hajj. These handbooks contain information on how air conditioners should be used. Unfortunately, in our study, more than $45 \%$ of the pilgrim candidates stated that they did not know how to use the air conditioner and that they did not think it is necessary to know. According to our study results, pilgrim candidates do not have enough awareness of this matter. In the literature, no research has been found to evaluate the knowledge of pilgrims on the use of air conditioning to prevent respiratory infections. It is suggested in this study that demonstrating the simple physical use of air conditioners to the pilgrim candidates can contribute to reducing the risk of illness and increasing awareness with the aim of preventing respiratory infections caused by air conditioning.

Nurses who have an important role in the provision of health services must take responsibility for the protection of pilgrim health (30). The needs of pilgrims should be determined by nurses (such as climate differences, preventive measures for respiratory infections, vaccination, lack of knowledge, individual hygiene, etc.) before the Hajj. Then, the content of the services to be offered should be planned and implemented. It is obvious that the care, education programs, and consultancy services that nurses offer for pilgrim health will contribute positively to the pilgrims' quality of life.

\section{Conclusion}

Pilgrims can encounter many health problems in the Hajj. Healthcare professionals should be able to determine the right care needed by pilgrims before and after the Hajj. Our research results showed that high age, low education status, presence of chronic disease affect the pilgrims' awareness and behaviors regarding RTI preventive measures. In the light of the data and results of the study, it can be concluded that vaccination and many non-pharmaceutical interventions were effective in preventing respiratory tract infections, which can be seen during the Hajj. However, the current protective interventions are mostly inadequate. The health of the pilgrims will be protected through preventive training and follow-ups. Moreover, this study is of great importance for the protection of older adults who are considered as one of the cultural heritages of Turkish society. It is thought that future studies will contribute to the protection of pilgrim health.

\section{Acknowledgments}

We are thanks to the Republic of Turkey Presidency of Religious Affairs for their support.

\section{Ethics}

Ethics Committee Approval: Before the study was conducted, the official permission from the Republic of Turkey Presidency of Religious Affairs was provided to conduct the research, and Ethics committee approval was obtained from Ankara Yıldırım Beyazıt University Clinical Research Ethical Board (2019-no: 16).

Informed Consent: Informed consent was obtained.

Peer-review: Externally peer-reviewed.

\section{Authorship Contributions}

Surgical and Medical Practices: B.Ç., B.i., Concept: B.Ç., Design: B.Ç., B.I., Data Collection or Processing: B.Ç., B.i.., Analysis or Interpretation: B.Ç., B.I., Literature Search: B.Ç., Writing: B.Ç.

Conflict of Interest: No conflict of interest was declared by the authors.

Financial Disclosure: The authors declared that this study received no financial support.

\section{References}

1. Organization WH. Public health for mass gatherings: key considerations: World Health Organization; 2015.

2. Memish ZA, Stephens GM, Steffen R, Ahmed QA. Emergence of medicine for mass gatherings: lessons from the Hajj. Lancet Infect Dis 2012;12:56-65.

3. Al-Tawfiq JA, Zumla A, Memish ZA. Respiratory tract infections during the annual Hajj: potential risks and mitigation strategies. Curr Opin Pulm Med 2013;19:192-197.

4. Republic of Turkey Presidency of Religious Affairs (2018) The number of people going to Hajj and Umrah according to the age groups. Available at: https://stratejigelistirme.diyanet.gov.tr/sayfa/57/istatistikler

5. Gatrad AR, Sheikh A. Hajj: journey of a lifetime. BMJ 2005;330:133-137.

6. Ahmed $\mathrm{QA}$, Arabi YM, Memish ZA. Health risks at the Hajj. Lancet 2006;367:1008-1015.

7. Abubakar I, Gautret P, Brunette GW, Blumberg L, Johnson D, Poumerol G, Memish ZA, Barbeschi M, Khan AS. Global perspectives for prevention of infectious diseases associated with mass gatherings. Lancet Infect Dis 2012;12:66-74.

8. Abdou AEA. Temperature Trend on Makkah, Saudi Arabia. Atmospheric and Climate Sciences 2014;4:457-481.

9. Charlton $C L$, Babady E, Ginocchio CC, Hatchette TF, Jerris RC, Li Y, Loeffelholz M, McCarter YS, Miller MB, Novak-Weekley S, Schuetz AN, Tang YW, Widen 
R, Drews SJ. Practical guidance for clinical microbiology laboratories: viruses causing acute respiratory tract infections. Clin Microbiol Rev 2019;32:e00042-18.

10. Al-Tawfiq JA, Gautret P, Benkouiten S, Memish ZA. Mass Gatherings and the Spread of Respiratory Infections. Lessons from the Hajj. Ann Am Thorac Soc 2016;13:759-765.

11. Erdem $H, A k$ O, Elaldi N, Demirdal $T$, Hargreaves $S$, Nemli SA, Cag $Y$, Ulug M, Naz H, Gunal O, Sirmatel F, Sipahi OR, Alpat SN, Ertem-Tuncer G, Sozen H, Evlice 0, Meric-Koc M, Dogru A, Koksaldi-Motor V, Tekin R, Ozdemir D, Ozturk-Engin D, Savasci U, Karagoz E, Cekli Y, Inan A. Infections in travellers returning to Turkey from the Arabian peninsula: a retrospective crosssectional multicenter study. Eur J Clin Microbiol Infect Dis 2016;35:903910.

12. Hashim S, Ayub ZN, Mohamed Z, Hasan H, Harun A, Ismail N, Rahman ZA, Suraiya $S$, Naing NN, Aziz AA. The prevalence and preventive measures of the respiratory illness among Malaysian pilgrims in 2013 Hajj season. J Travel Med 2016;23:tav019.

13. Benkouiten S, Al-Tawfiq JA, Memish ZA, Albarrak A, Gautret P. Clinical respiratory infections and pneumonia during the Hajj pilgrimage: $A$ systematic review. Travel Med Infect Dis 2019;28:15-26.

14. Hoang VT, Gautret P. Infectious diseases and mass gatherings. Curr Infect Dis Rep 2018;20:44.

15. Al-Abdallat MM, Rha B, Alqasrawi S, Payne DC, Iblan I, Binder AM, Haddadin A, Nsour MA, Alsanouri T, Mofleh J, Whitaker B, Lindstrom SL, Tong S, Ali SS, Dahl RM, Berman L, Zhang J, Erdman DD, Gerber SI. Acute respiratory infections among returning Hajj pilgrims-Jordan, 2014. J Clin Virol 2017;89:34-37.

16. Hoang VT, Sow D, Dogue F, Edouard S, Drali T, Yezli S, Alotaibi B, Raoult D, Parola P, Pommier de Santi V, Gautret P. Acquisition of respiratory viruses and presence of respiratory symptoms in French pilgrims during the 2016 Hajj: A prospective cohort study. Travel Med Infect Dis 2019;30:32-38.

17. Alzeer AH. Respiratory tract infection during Hajj. Ann Thorac Med 2009;4:50-53.

18. Benkouiten $S$, Brouqui $P$, Gautret P. Non-pharmaceutical interventions for the prevention of respiratory tract infections during Hajj pilgrimage. Travel Med Infect Dis 2014;12:429-442.
19. Gautret P, Benkouiten S, Gaillard C, Parola P, Brouqui P. Camel milkassociated infection risk perception and knowledge in French Hajj pilgrims. Vector Borne Zoonotic Dis 2013;13:425-427.

20. Gautret P, Soula G, Parola P, Brouqui P. Hajj pilgrims' knowledge about acute respiratory infections. Emerg Infect Dis 2009;15:1861-1892.

21. Raja W, Aziz A, Hassan TB, Jalil M, Niazi IU, Jawaid N, Tariq M. Disease patterns among Hajj pilgrims attending medical facilities of Pakistan Hajj medical mission 2016 (1437 HIJRI). Pakistan Armed Forces Medical Journal 2017;67:825-831.

22. Gautret P, Benkouiten S, Griffiths K, Sridhar S. The inevitable Hajj cough: surveillance data in French pilgrims, 2012-2014. Travel Med Infect Dis 2015;13:485-489.

23. Gautret $P$, Vu Hai V, Sani $S$, Doutchi M, Parola P, Brouqui P. Protective measures against acute respiratory symptoms in French pilgrims participating in the Hajj of 2009. J Travel Med 2011;18:53-55.

24. Parker S, Gaines J. Saudi Arabia: Hajj/Umrah Pilgrimage. Travelers' Health: Yellow Book, 4th Chap, 2018.

25. Memish ZA, Al Rabeeah AA. Health conditions for travellers to Saudi Arabia for the Umra and pilgrimage to Mecca (Hajj)-2014. J Epidemiol Glob Health 2014;4:73-75.

26. Barasheed O, Rashid H, Heron L, Ridda I, Haworth E, Nguyen-Van-Tam J,

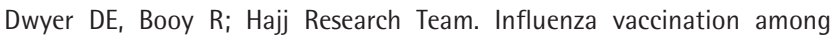
Australian Hajj pilgrims: uptake, attitudes, and barriers. J Travel Med 2014;21:384-390.

27. Alqahtani $A$, Rashid $H$, Heywood A. Vaccinations against respiratory tract infections at Hajj. Clin Microbiol Infect 2015;21:115-127.

28. Moran KR, Del Valle SY. A meta-analysis of the association between gender and protective behaviors in response to respiratory epidemics and pandemics. PLoS One 2016;11:e0164541.

29. Qari S. The Hajj: Hazards of Heat Exposure and Prevalence of Heat IIInesses among Pilgrims. Journal of Liaquat University of Medical \& Health Sciences 2019;184:252-257.

30. Nasir DM. Exploring the health information needs of pilgrims for the protection against infectious diseases during mass muslim gatherings (HAJJ) 2017. 